\title{
Technical Education in the Context of Sustainable Development
}

\author{
Irina Nazarova \\ Bauman Moscow State Technical University \\ 5/1 2d Baumanskaya St. \\ Moscow, Russia 105005 \\ E-mail: nazirrad@yandex.ru
}

\begin{abstract}
The article deals with the problem of reforming Russian education. By analogy with the post-non-classical paradigm of science, it is proposed to build an educational strategy on the principles of complexity, openness, nonlinearity, human dimension. The importance of holistic thinking in the implementation of this strategy, especially for engineering education, is substantiated. The advantage of contextual learning in this process is shown. It is proposed to consider sustainable and coordinated development of various complex structures in the world as a context.
\end{abstract}

Keywords-educational reform; post-non-classical scientific paradigm; sustainable development; technical education

\section{INTRODUCTION}

The problem field related to the investigation of educational institute is "doomed" to constant broadening and growing. The reason is most obviously related to the fact that all the recent attempts to reform the institute in question overshade its main object, the Human. We are inclined to think that the humanitarian mission of universities has not only simply remained topical but gained in its topicality. By analogy with post-non-classical scientific paradigm, whose objects have become complex, open, dynamic man-sized systems, we can claim that modern education should only have a humanistic guide mark for the choice of aims, tasks, tools and methods of their achievement and solution. This original "paradigm shot" (V. Stepin) makes actual the search of new educational technologies satisfying the challenges of natural, social and technical realities.

\section{POST-NON-ClasSiCAL SCIENTIFIC PARADIGM}

What is essential in the search of educational technologies is the understanding of the fact that in the conditions of raising complexity and vagueness of the evolution of the social system, whose element the educational institute is, the human is viewed as "a special parameter of order that influences the process of educational communication, the results of scientific knowledge on the whole. That means that the control and maintenance of the scientific knowledge of the kind requires totally different experience than that developed by object knowledge" [1].
Russian education remains still in quite an unstable state being influenced by various and multi-faceted actions of the market, bureaucracy, Bologna system requirements and the forming society of knowledge [2]. That is why it is most logical in the given conditions to appeal to the post-nonclassical scientific paradigm characterized by the principles of complexity, openness, nonlinearity, and vagueness. These principles can become certain guide marks for making a corresponding educational strategy satisfying the challenges of the modern stage of civilized development.

\section{CONTEXT LEARNING}

The building of the specified strategy makes actual the methodological agenda of investigating human-sized systems that means the search of adequate methods of investigating the human not only as an object but also as the subject of professional activity. Knowledge of the kind is the one that helps building the corresponding educational strategy.

Let us base ourselves on and start with a six-year-old example. In June 2012 the largest conference of the century, "RIO+20" took place. However, during the conference it was sadly admitted that in the course of the last two decades the trinity of social economic ecological model had been violated. In the Conference's Joint statement it was specially stressed that education and democratization of knowledge were the basics priorities of development, which are to strengthen the creative, innovational and industrial potential by creating the conditions for sustainable development of economy.

Without diminishing the role of education in the process let us stress merely the special significance of technical education. There is no need to prove that technical society is related to the changes of the planetary scale including the human, their way of life, thinking, communication, values, icons, etc. that is why the question of realizing and understanding the trinity of social economic ecological model of development requires developed reflection from the representatives of the technical society. It is especially topical for the stage of hardware and technology design. This requirement is explained by the fact that reflection is aimed at complex systemic education related to both ultimate bases of existence and thinking and to the world of human culture on the whole [3]. What can help realize the relation of the 
technical activity to the historical and social creative work is a developed holistic thinking, which is defined as "the understanding of the broad or even global context of any problem under investigation, that means the ability to contextualize knowledge, and also the understanding of general laws of integration, co-evolution and consistent sustainable development of various complex structures in the world" [4].

If we concretize this thesis in relation to education than it will be context learning that can promote the development of holism in thinking procedures. The founder of the concept of "complex thinking" Edgar Morin sets a number of tasks before the education of the future. These tasks are essentially aimed at measuring the ways of thinking to admit vagueness as an obligatory component of learning overcoming both egocentrism and sociocentrism of modern civilization prioritizing polycentrism. Edgar Morin notes that isolated information is not enough for learning as it is. It only gains sense if placed into a certain context [5].

If we appeal to international and interstate documents and legislative acts, materials of international conferences, numerous documents of UNESCO UNEP of the last decades, we can notice the increasing interest for the educational institute in the context of sustainable development. Hence, sustainable development can quite reasonably claim the role of the context like this [6].

Back in October 1987 at the UN General Assembly Plenary Session the resolution was adopted that defined the basic principles of sustainable development, where it was stressed that meeting the requirement of the present time was characteristic of it, yet without creating the threat to the ability of the generations to come to meet their own needs [7].

In 2002 the UN General Assembly stated the period of 2005-2014 the UN Decade of Education in the context of sustainable development. The task of realizing and helping the transition to sustainable development with the increase of the quality of teaching was put before the educational institute. Among numerous initiatives put forward to solve the given task it is worth mentioning the development of the Strategy of sustainable development for the UNECE. The strategy was adopted at a special meeting of the representatives of the Ministry of Environmental Conservation and the Ministry of Education of UNECE in March 2005 in Vilnius. The main aim of the Strategy was to encourage the UNECE member states to develop and include ESD (Education for Sustainable Development) into their educational systems, including informal education and enlightenment. It is worth mentioning that this meeting set up concrete stages and steps towards the fulfillment of the Strategy at regional and national levels, including the necessity to develop National Educational Strategies in the context of sustainable development and National Plans of their fulfillment.

\section{UNITED NATIONS ECONOMIC COMMISSION FOR EUROPE STRATEGIES}

To put the Strategy of the United Nations Economic Commission for Europe briefly, we should say that it aimed the education in the context of sustainable development at the transition from "simple transmission of knowledge and skills necessary for existence in modern society, to the readiness to act and live in quickly changing conditions, to take part in planning social development, to learn to foresee the consequences of actions undertaken, including the possible consequences in the sphere of sustainability of natural ecosystems and social structures" [8]. During this refocusing, the level of social activity of the learners should increase, which presupposes conscious active participation in various forms of social practices, the increase of personal responsibility for the choice of strategy of the life vector of development in the conditions of vagueness and the increasing complexity of problematic situations. It is quite obvious that the substantive educational model does not in the slightest correspond to the changed conditions of the modern society. That is why the transition to the personcentered educational model is most natural; this model unlike the substantive one puts the stress onto the refocusing of education from studying the existing knowledge to the ability of individually finding it. The given model is very closely related to the necessity of developing information culture in the widest sense of the term [9]. Here belongs all the body of knowledge and skills necessary for the nonstopping work with the ever increasing volumes of information to solve topical issues of different character and complexity. In other words, to implement the new educational strategy of sustainable development, a totally different object of activity is needed - transdisciplinary, non-local, communicatively related to the overall hierarchy of reality levels, including cosmological reality" [10].

It is especially topical for technical education because engineers are always involved into design process and the design is becoming a feature of practically every kind of activity (engineering per se, planning, administrative work, political, reformative, scientific, educational issues, etc.). That is why design theoreticians suggested introducing a new name for design culture. This kind of culture is often called The Design, which implies the total character of design as a unity being an important element of activity in all its diversity, including thinking. What is important for design practice is the ability of multilayered thinking, creative search independently of the conceptual data.

However, the developed social economical model "imposes" and "pushes" certain kinds of activity, poses definite tasks, creates most concrete scenarios of their solution, of which dehumanization, technocratization, commercialization is characteristic. That is why the model of sustainable development is an adequate reply to the challenges of the technocratically focused civilization [11].

\section{FORMATION OF A NEW TYPE PERSONALITY}

The transition to the given model requires serious modifications in all spheres of activity, including thinking 
activity. It is most obvious that the educational institute plays an important role in this process by being the instrument of forming a totally new subject of activity having complex thinking corresponding to the Complexity methodology. The characteristic features of the modern historical situation in the given methodology are innovation design determination, radical pluralism, multiplication of differences, hyperdynamism, and continuity of all modifications, and also the unpredictability of the behaviour of the systems developed as a result of all this [12].

Thus, the educational institute gets a new social order to form a new type personality, a personality with a high level of general and information culture, able to think globally and to take important decisions based upon the preliminary analysis of possible negative consequences in practical area. The fulfillment of such a difficult order presupposes setting new aims and posing the tasks for the educational institute. In order to create a new substantive educational resource, it is necessary to develop corresponding tools. As the basis of the content structure it is important to lay the methodological, theoretical and didactical foundations. The renewed education becomes closely related to other social institutes directly influencing their state, functioning and development [13].

The world pedagogical practice suggests, the solution to this task is possible at the level of constructive polylogue through the "cross-fertilization" of the ideas of the natural scientific, technological and humanitarian culture, including national peculiarities, moral, esthetic, and religious values and attitudes. Today sustainable development is viewed as a new educational vector directing all the structural components towards post-non-classical practices with their vagueness, complexity, openness, nonlinearity, humansizedness [14].

In other words, education is the prerequisite of reaching a sustainable future and is its prior tool. At the Summit on SD during the UN 70th General Assembly which adopted the Agenda in the area of Sustainable development up to 2030 the education was announced the most important mechanism of reaching the 17 new global Aims of Sustainable development (ASD). Among the 17 ASDs we will consider the one which is related to education: "To provide comprehensive and high-quality education and encourage the possibilities of life-long learning for everybody". This aim presupposes for its realization the solution of a number of tasks, among which we will consider the following task: "By 2030 to ensure that all learners get knowledge and skills necessary to promote sustainable development, among other things through the learning based on the problems of sustainable development, the propaganda of sustainable way of life, human rights, gender equality, peace and nonviolence culture and the concept of global citizenship and the understanding of the value of cultural diversity and the contribution of culture into sustainable development" [15].

\section{TECHNICAL EDUCATION FOR SUSTAINABLE DEVELOPMENT}

If we extrapolate this aim onto technical education, we should conclude the following idea: the development of a modern course for engineers is impossible without integration based on sustainable development of modern civilization. It is essential that technical education based on sustainable development presupposes the necessity of developing the ability to be quickly and effectively modified. Basically, it should not only take into consideration the today's requirements but also the perspective, which in the system complexity conditions most often remains vague even in the risks category. That is why it is important to rely on the co-evolution principle as the guide mark of engineer education and activity, i.e. to remember that the problems of technological development of society and environment are inseparable, and for their solution the reliance on the integration of multi-subject knowledge of physics, biology, synergy, philosophy, global ethics, and other is presupposed [16].

Russian school of sustainable development based on the conceptual ideas of the thinkers such as V.I Vernadskiy, E.S. Bauer, N.N. Moiseev, P.G. Kuznetsov, B.E. Bolshakov, O.L. Kuznetsov, and others, continues paying special attention to the problem of developing an interdisciplinary approach in the field of design of natural anthropogenic systems. The investigation of the kind allows setting the corresponding tasks technical education faces in the process of its reforming in the context of sustainable development. It is important to mention that the context in question aims the educational institute not only at the necessity of acquiring knowledge and skills of an activity approach but also at the formation of a corresponding system of values, which allows the professional to remain a certain "servant of humanism" in the context of choice and decision-taking in the conditions of vagueness.

For this reason the thought expressed by P.G. Kuznetsov for environment protecting engineering on a sustainable basis is very topical. The following three logic types correspond in his view to any creative process:

- Investigation logic (logic of thinking) - "from nature to ideas";

- Design logic - "from ideas to nature";

- Synthesis of these logics as design of sustainable development based on the Life development law [17]

\section{CONCLUSION}

The new model of civilized sustainable development of the third millennium can be actualized only on the basis and with the help of its most important subsystem, the educational institute, because sustainable development requires drastic changes in all activity spheres, including thinking activity. It is especially topical for technical education because the technocratic style of thinking and the corresponding activity types aimed at effectiveness only can be incommensurable with the conditions of further existence 
of a human as a biological species. In order to "release the stress" between the human and the nature it is necessary to find a method of "breeding" engineers, the servants of humanism, for whom the leading guide mark in all activity types will be the Reverence for Life principle of Albert Schweitzer. The "what to do" question should not overshadow the "how to do" question.

\section{REFERENCES}

[1] Yaroslavtseva E.I. Postnonclassical Science and Modern Human Practice. Available at: http://iphras.ru/page24711508.htm

[2] Joint Announcement of Economic and Social counsels and similar institutes and other representatives of Civil Society of European Union and BRICS countries about the UN Conference on the Issue of Sustainable Development, Rio de Janeiro, June19th, 2012. Sustainable Development Institute of the Public Chamber of the Russian Federation. Available at: http://www.sustainabledevelopment.ru/upload/File/2012/zayavl_ES_ BRICS_19_06_2012.pdf

[3] Vlasov S.A., Nazarova I.R. Industrial design as an element of project culture. Humanities Bulletin of BMSTU, 2014, no. 1 (15). Available at: http://hmbul.bmstu.ru/catalog/hum/phil/159.html

[4] Knyazeva E.N., Kurdyumov S.P. The Bases of Synergy. Man designing himself and their future. No. 21. Izd. stereotip. The "Synergy: past to future" series. Moscow, Knizhny dom "Librokom" Publ., 2011.

[5] Morin E. Seven complex lessons in education for the future. Available http://bib.convdocs.org/v25934/морен_э. образование в будущем _семь_неотложных_задач

[6] Zemtsov B.N. Right as World Outlook Value of the Power (XX Century) // Tomsk State university journal of history. 2014. № 4 (30). P. 28-34.

[7] Our Future: the text of the World Commission on Environment and Development report, 1987, Moscow, Progress Publ., 1989.

[8] National Education Strategy for sustainable development in the Russian Federation. Available at: http://www.unece.org/fileadmin/DAM/env/esd/Implementation/NAP/ RussianFederationNS.r.pdf C.1

[9] Ivlev Yu. V., Ivlev V.Yu., Ivleva M.L. Logical-argumentative basics of educational culture // Proceedings of 4th International Conference on Education, Language, Art and Intercultural Communication (ICELAIC 2017) Part of the series ASSEHR. Moscow, Russia. Pp. 173-177.

[10] Arshinov V.I., Burov V.A., Gordin P.M. The establishment of a subject of post-non-classical science and education. Synergy paradigm. The synergy of education. Moscow, Progress-Traditsiya Publ., 2007, pp. 114-136.

[11] Suzdaleva T.R. Migratory processes in the context of geopolitics // Vestnik Tomskogo gosudarstvennogo universiteta-Filosofiyasotsiologiya-politologiya-Tomsk state university journal of philosophy sociology and political science. 2016. № 3 (36). P. 237244. DOI: $10.17223 / 1998863 \mathrm{X} / 35 / 25$

[12] Grechko P.K. Paradigmal euristics of complexity in the modern socio-humanitarian learning // RUDN Journal of Philosophy, 2012, no. 1 , pp. 5-21.

[13] Oseledchik M.B., Ivlev V.Yu., Ivleva M.L. A new paradigm for analysing knowledge transfer processes // Proceedings of 4th International Conference on Education, Language, Art and Intercultural Communication (ICELAIC 2017) Part of the series ASSEHR. Moscow, Russia. Pp. 766-770

[14] Lebedev S.A. The Structure of Scientific Rationality // Voprosy filosofii. 2017. № 5. P. 66-79.

[15] The modification of our world. The agenda in the field of sustainable development up to 2030, p. 22. Available at: https://sustainabledevelopment.un.org/post2015
[16] Lebedev S.A. The Reassembly of the Epistemology // Voprosy filosofii. 2015. № 6. P. 53-64

[17] Bolshakov B.E., Kuznetsov O.L. P.G. Kuznetsov and the problem of sustainable development of the mankind in the "nature-societyhuman" system. Report at the international Symposium "Time and Space in the evolution of the global "nature-society-human" system ", dedicated to the cherished memory of the outstanding Russian scientist Pobisk Georgievich Kuznetsov, Moscow, the 14-15th December 2001. Available at: http://noocivil.esrae.ru/pdf/2014/4/1267.pdf. 